\title{
Calf presence and estrous response, ovarian follicular activity and the pattern of luteinizing hormone in postpartum Bos indicus cows
}

\author{
Eduardo Gularte Xavier ${ }^{1}$, Carlos Salvador Galina ${ }^{2}$, Claudio Alves Pimentel ${ }^{3}$, \\ Sandra Fiala Rechsteiner ${ }^{4, £}$, Martin Maquivar ${ }^{5}$ \\ ${ }^{1}$ Granja 4 Irmãos, Pelotas, RS, Brazil. \\ ${ }^{2}$ Departamento de Reproducción Animal, Facultad de Medicina Veterinaria y Zootecnia,UNAM, México. \\ ${ }^{3}$ Haras Santa Anita do Minuano, Capão do Leão, RS, Brazil. \\ ${ }^{4}$ HISTOREP, Instituto de Biologia, UFPel, Pelotas, RS, Brazil \\ ${ }^{5}$ Department of Animal Sciences. Washington State University, Pullman, Washington, USA.
}

\begin{abstract}
The main objective of the present experiment was to assess the effect of temporary weaning on the onset of estrus, ovarian follicular activity and secretion of luteinizing hormone in Bos indicus cows. Forty six mature cows were divided into three groups 1) calves were weaned for $72 \mathrm{~h}$ allowing auditory, olfactory and visual contact with their dams (VISUAL, $\mathrm{n}=17$ ), 2) calves without contact with their dams for $72 \mathrm{~h}(\mathrm{NC}$, $\mathrm{n}=17$ ) and 3) calves not weaned and in constant contact with their dams (CTRL, $n=12)$. Estrus was synchronized in all cows using CIDR for 9 days plus $2 \mathrm{mg}$ of estradiol benzoate given at CIDR insertion. The VISUAL group had a greater $(\mathrm{P}<0.05)$ proportion of cows in estrus (76.5\%) compared to the CTRL group (16.7\%), but no differences were found when compared to the NC group $(58.8 \%)$. The VISUAL group had a greater proportion of animal that ovulated $(76.5 \%)$ compared to CTRL (33.3\%) and $\mathrm{NC}$ groups $(64.7 \% ; \mathrm{P}=0.059)$. Duration of estrus was shorter $(\mathrm{P}=0.04)$ in the VISUAL $(8.4 \pm 4.4$ hours) than in the $\mathrm{NC}(12.9 \pm 13.4$ hours $)$ however, CTRL treatment ( $11 \pm 1.4$ hours) was not different from either of these two groups. LH concentration after implant removal was similar among treatments and started to increase at $36 \mathrm{~h}$ post CIDR removal. Only in the CTRL group was there an obvious increase by $54 \mathrm{~h}$ after implant removal. Follicular size increased in diameter from $36 \mathrm{~h}$ and were evident in treatments and control groups by 60 $\mathrm{h}(\mathrm{P}<0.05)$. The VISUAL treatment increased the number of cows ovulating and shortened the length of estrus. VISUAL and NC groups showed a similar response in follicular growth and pattern of circulating LH because of treatment.
\end{abstract}

Keywords: Bos indicus, LH, postpartum, temporary weaning.

\section{Introduction}

Productive performance in beef cattle is closely linked to the reproductive efficiency of the herd especially during the postpartum period (Chenoweth, 1994). Resumption of ovarian activity is affected by many factors, such as forage availability, negative energy balance after parturition and the presence of the calf (Lamb et al., 1999; Ungerfeld et al., 2011).
Following calving, cows experienced a period of ovarian inactivity known as postpartum anestrus, characterized by suppressed ovarian follicular growth, lack of responsiveness to gonadotropin release and absence of estrus. This phenomena is more accentuated in Bos indicus cattle due to the low body condition scores observed at calving, strong maternal characteristics and the deficient nutritional management during the first 50 days after calving (Baruselli et al., 2004; Sartori et al., 2010). In fact, zebu cattle shows resumption of ovarian activity around 100 days postpartum (Galina and Arthur, 1989), although recent evidence, Diaz et al. (2017) has shown that this timeline could be shortened. Williams et al. (1990) suggested that the effect of suckling prolonged the anestrus postpartum and that calf separation might hasten the onset of ovarian activity and LH secretion. In Bos taurus cows, the presence of a non-suckled calf delays the first ovulation postpartum (Hoffman et al., 1996) while Viker et al. (1993) demonstrated that the suckling stimuli produced by the calf prolong postpartum anestrus. Under tropical conditions, Webb et al. (2004) working with weaning systems reported that Bos indicus cows in visual but not physical contact (suckling) with their calves showed better reproductive response than those with total lack of contact with their offspring. Partial and/or complete removal of the calf can result in larger amounts of circulating gonadotropins, especially LH; this procedure demands extra resources and labor, thus limiting the use of this approach in the tropics (Abeygunawardena and Dematawewa, 2004). However, weaning for a short period of time may induce a release of gonadotropins and follicular growth and ovulation is Bos indicus cattle. The objectives of the present study were to evaluate the effect of temporary weaning combined with hormonal treatment on the onset of estrus and the resumption of ovarian function in Bos indicus cows.

\section{Material and Methods}

All procedures involving animals and their management were approved by the Committee for the Use of Animals in Teaching and Research of the Faculty of Veterinary Medicine of the National University of Mexico. 


\section{Location of research animals}

The present study was undertaken at the Centre for Teaching, Research and Extension in Tropical Cattle of the Faculty of Veterinary Medicine, National University of Mexico, State of Veracruz, Mexico at $20^{\circ}$ $4^{\prime} \mathrm{N}$ and $97^{\circ} 653^{\prime} \mathrm{W}$ with a climate classified as tropical humid.

\section{Animals and treatments}

Multiparous suckling Brahman (Bos indicus; $\mathrm{n}$ $=46$ ) cows with an average postpartum interval of 50 days from 4 to 14 years old with a body condition score between 2.5 and 3.5 (scale 1 thin to 5 obese; Edmonson et al., 1989) were used in this study. Cows were randomly assigned by age, body weight and reproductive status to receive one of three treatments:
1) Calves were weaned for $72 \mathrm{~h}$ but in auditory, olfactory and visual contact with their dams, VISUAL, $\mathrm{n}=17$ ); 2) cows with no type of contact with their calves for $72 \mathrm{~h}$; (NC, $\mathrm{n}=17)$, and 3 ) control treatment where calves were not weaned and remained with their dams (CTRL, $n=12$ ). Body weight of the cows at the onset of the study was $404.4 \pm 56.1 \mathrm{~kg}$ (VISUAL), $415.2 \pm 58.5 \mathrm{~kg}(\mathrm{NC})$ and $410.3 \pm 52.3 \mathrm{~kg}$ (CTRL). Estrus was synchronized in all cows with use of a Controlled Intravaginal Progesterone Releasing Device (CIDR, Zoetis, Mexico) plus an intra-muscular injection of $2 \mathrm{mg}$ of estradiol benzoate at implant insertion. The implants remained intravaginally for 9 days and on implant withdrawal, cows from the VISUAL and NC treatment groups were separated from their calves for $72 \mathrm{~h}$ as previously described (Fig. 1). All animals grazed on native pastures (Paspalum spp.) for the duration of the experiment.

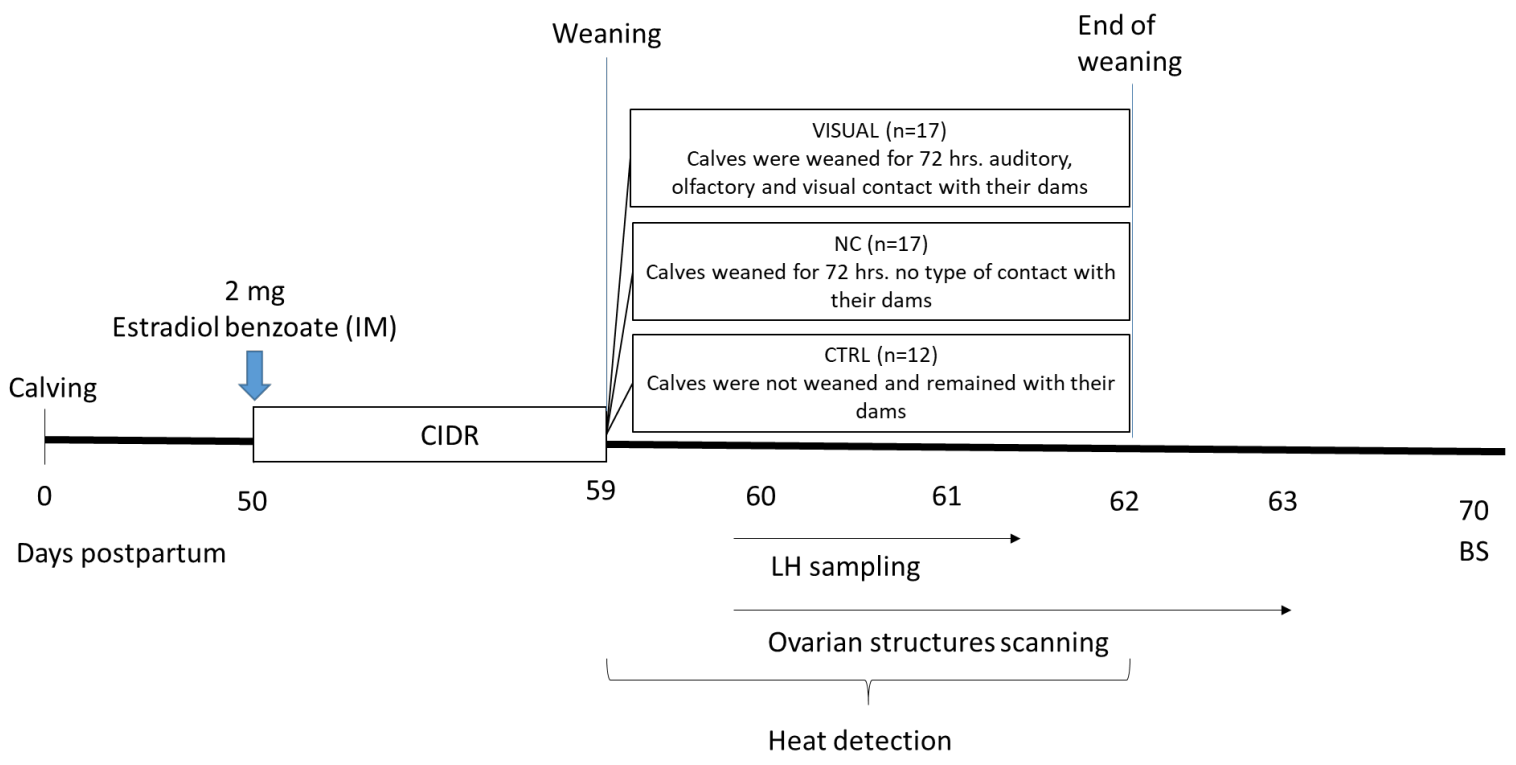

Figure 1. Experimental design.

\section{Sexual behavior}

Cows were kept under constant visual observation for $72 \mathrm{~h}$ starting the day of the implant removal for detection of estrus according to the procedure recommended by Orihuela et al. (1983). Onset of estrus was defined as the time when the cow allowed at least three mounts in a period of $4 \mathrm{~h}$ or less. Estrus was defined as when three or more mounts were first received or performed by a cow with no more than $3 \mathrm{~h}$ between mounts (Orihuela et al., 1983).

\section{Reproductive evaluations}

Serum progesterone concentration determined that $44 \%$ of cows were cycling at the beginning of the experiment; these animals were distributed equally among treatments. Ovarian evaluations were performed using an Aloka model SSD - 500 with a linear transductor probe of $7.5 \mathrm{MHz}$. All cows were tested by ultrasound for the presence of ovarian follicles every $6 \mathrm{~h}$ starting $24 \mathrm{~h}$ (Day 60) after implant removal until $102 \mathrm{~h}$ (day 63) or until ovulation occurred. Ovulation was defined as the time when a follicle larger than $8 \mathrm{~mm}$ in diameter was no longer found to be present in the ovary.

Ovulation was validated by the presence of a functional corpus luteum (CL) 7 days after (day 70) the last ultrasound and substantiated by progesterone concentrations greater than $1 \mathrm{ng} / \mathrm{ml}$.

\section{Blood sampling and hormone analysis}

Blood samples were collected during the ultrasound evaluations and also twice a week for 4 weeks before the start of hormonal treatment to establish the percentage of females in anestrus. Other samples were taken to measure progesterone concentration at the time of implant removal and 7 days later after calves were reunited with their dam. Additionally, following CIDR withdrawal/weaning of the calves, all cows underwent intensive blood sampling for LH determination (from 24 to 66 hours) 
along with ultrasound examination of the ovaries. Blood samples were taken by tail vein or artery puncture, centrifuged at $1500 \mathrm{rpm}$ for 10 minutes, and kept frozen until liquid radioimmunoassay (RIA) specific for bovine $\mathrm{LH}$ with $120 \mathrm{~h}$ of incubation at $4^{\circ} \mathrm{C}$. USDA-bLH radiolabeled [I125] as marker using iodine IODO-GEN technique (PereraMarin et al., 2005). The intra-assay coefficient of variation was $7.8 \%$ (1.8 $\mathrm{ng} /$ tube $)$ and the assay sensitivity was $0.02 \mathrm{ng} /$ tube. All samples were analyzed in one duplicate assay. Plasma progesterone concentration was analyzed in duplicate using a commercial radioimmunoassay analysis (RIA) kit (Coat-a-Count, Siemens Medical Solutions Diagnostics, Los Angeles, CA, USA). Coefficient of variation for the assay was $4.1 \%$ and sensitivity was $0.1 \mathrm{ng} / \mathrm{ml}$.

\section{Statistical analysis}

Variables measured were implant withdrawal/weaning to onset of estrus and end of estrus, time of ovulation and time of LH increase, as well as onset of estrus to ovulation, end of estrus to ovulation and time of LH increase to ovulation. Variables were analyzed using a general lineal model, the GLM procedure in the SAS statistical software (2004). LH concentration and dominant follicle diameter were analyzed by ANOVA PROC MIXED procedure in SAS, using time as a repeat measure. An LH surge was defined as an increase in $\mathrm{LH}$ concentration of at least two standard deviations above the individual baseline observed during the first $48 \mathrm{~h}$ of intensive bleeding (Mikeska and Williams, 1988). Cows that had ovulated and shown estrus by a Chi-square test.

\section{Results}

No statistical differences were observed in estrous response after implant withdrawal between cows from the VISUAL (76.5\%) and NC (58.8\%) treatment groups. However, cows in the VISUAL group had a greater $(\mathrm{P}<0.05)$ estrous response compared to CTRL treatment $(16.7 \%)$. No differences were detected among cows of the NC and CTRL groups. Furthermore, the VISUAL group tended to have a greater percentage of animals that ovulated $(76.5 \%)$ compared to the $\mathrm{NC}$ treatment $(64.7 \%)$ and control group $(33.3 \%)(\mathrm{P}=0.059)$. Females from the VISUAL group had a shorter estrus $(8.4 \pm 4.4$ hours) than the NC group $(12.9 \pm 13.4$ hours; $\mathrm{P}=0.04)$. However, no differences among the VISUAL and NC groups were seen when compared with the CTRL group ( $11 \pm 1.4$ hours $)$.

Overall, estrous response to treatment, regardless of weaning status, was $54.3 \%$, and overall ovulation rate was $60.8 \%$. Onset of estrus for all treatments was around $35 \mathrm{~h}$ after implant withdrawal (Tab. 1). Animals from the VISUAL group had ovulated by $67 \mathrm{~h}$ after weaning/implant withdrawal and cows from the $\mathrm{NC}$ and CTRL groups around 72 $\mathrm{h}$, this difference was not significant. Groups showed a similar pattern of increases in LH concentration; the VISUAL group at $42 \mathrm{~h}$, the NC and CTRL groups around $47 \mathrm{~h}$. Interestingly, in the CTRL group from the onset of estrus to ovulation, only one animal that exhibited estrus ovulated, whereas the remaining animals $(n=3)$ that ovulated did not show overt signs of estrus.

LH concentration started to increase at $36 \mathrm{~h}$ in the three groups. However, only in the CTRL group was there any evident increase in LH by $54 \mathrm{~h}$ after implant removal compared to cows in the VISUAL and NC groups (Fig. 2).

Additionally, $\mathrm{LH}$ increase for all treatments occurred around $25 \mathrm{~h}$ (Tab. 1). Ovulation occurred around $22 \mathrm{~h}$ after cessation of estrus. In terms of follicular growth $60 \mathrm{~h}$ from implant withdrawal, the diameter of dominant follicles of cows in the VISUAL and NC groups were larger $(\mathrm{P}<0.05)$ than those of cows from the CTRL group (Fig. 3).

Table 1. Effect of the presence or absence of the calf after an estrous synchronization program on reproductive variables in postpartum Bos indicus cows.

\begin{tabular}{lllll}
\hline \multirow{2}{*}{ Variables (h) } & & VISUAL & $\mathrm{NC}$ & \multicolumn{1}{c}{ CTRL } \\
& & $\mathrm{n}=17$ & $\mathrm{n}=17$ & $\mathrm{n}=12$ \\
\hline \multirow{3}{*}{$\begin{array}{l}\text { Implant withdrawal/ } \\
\text { weaning to: }\end{array}$} & Onset of estrus & $34.9 \pm 6.4$ & $34.8 \pm 6.2$ & $36.5 \pm 10.6$ \\
\cline { 2 - 5 } & End of estrus & $42.3 \pm 5.5$ & $46.7 \pm 4.2$ & $46.5 \pm 9.2$ \\
& Ovulation & $67.4 \pm 11.3$ & $72.0 \pm 14.9$ & $73.5 \pm 12.4$ \\
\hline \multicolumn{2}{c}{ LH increase } & $42.5 \pm 8.2$ & $47.4 \pm 11.8$ & $48.0 \pm 8.5$ \\
\hline \multicolumn{2}{c}{ Onset of estrus to ovulation } & $32.7 \pm 8.9$ & $34.3 \pm 10.7$ & $31.0^{*}$ \\
& End of estrus to ovulation & $24.7 \pm 10.7$ & $22.2 \pm 10.8$ & $20.0^{*}$ \\
& LH increase to ovulation & $24.9 \pm 8.0$ & $24.5 \pm 8.6$ & $25.5 \pm 5.7$ \\
\hline
\end{tabular}

VISUAL = calves partially removed; $\mathrm{NC}=$ calves completely removed; $\mathrm{CTRL}=$ calves were not removed; Variables are expressed in means $\pm \mathrm{SD}$; Values represent one observation of a cow that displayed estrous behavior and had an ovulation. 


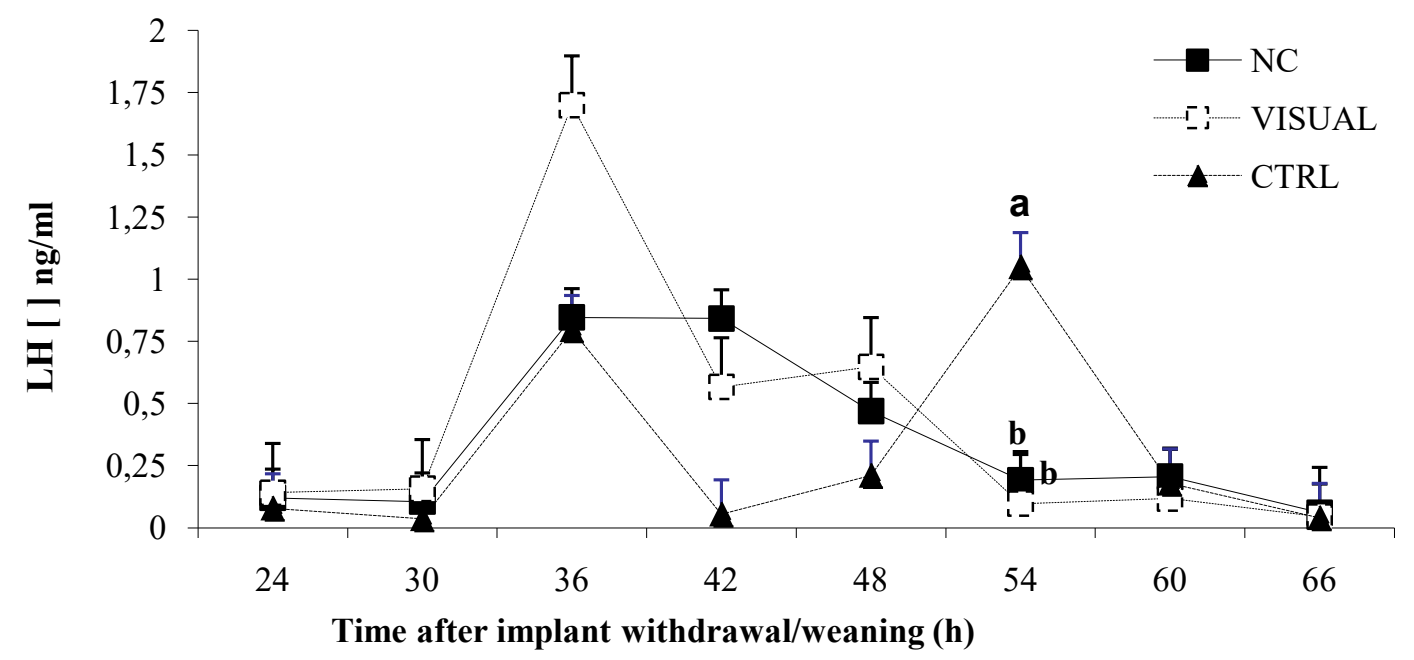

Figure. 2. Effect of the presence or absence of the calf after an estrous synchronization program on luteinizing hormone in postpartum Bos indicus cows; VISUAL = calves partially removed; $\mathrm{NC}=$ calves completely removed; $\mathrm{CTRL}=$ calves were not removed; . Different superscripts among time points denotes a difference $(\mathrm{P}<0.05)$.

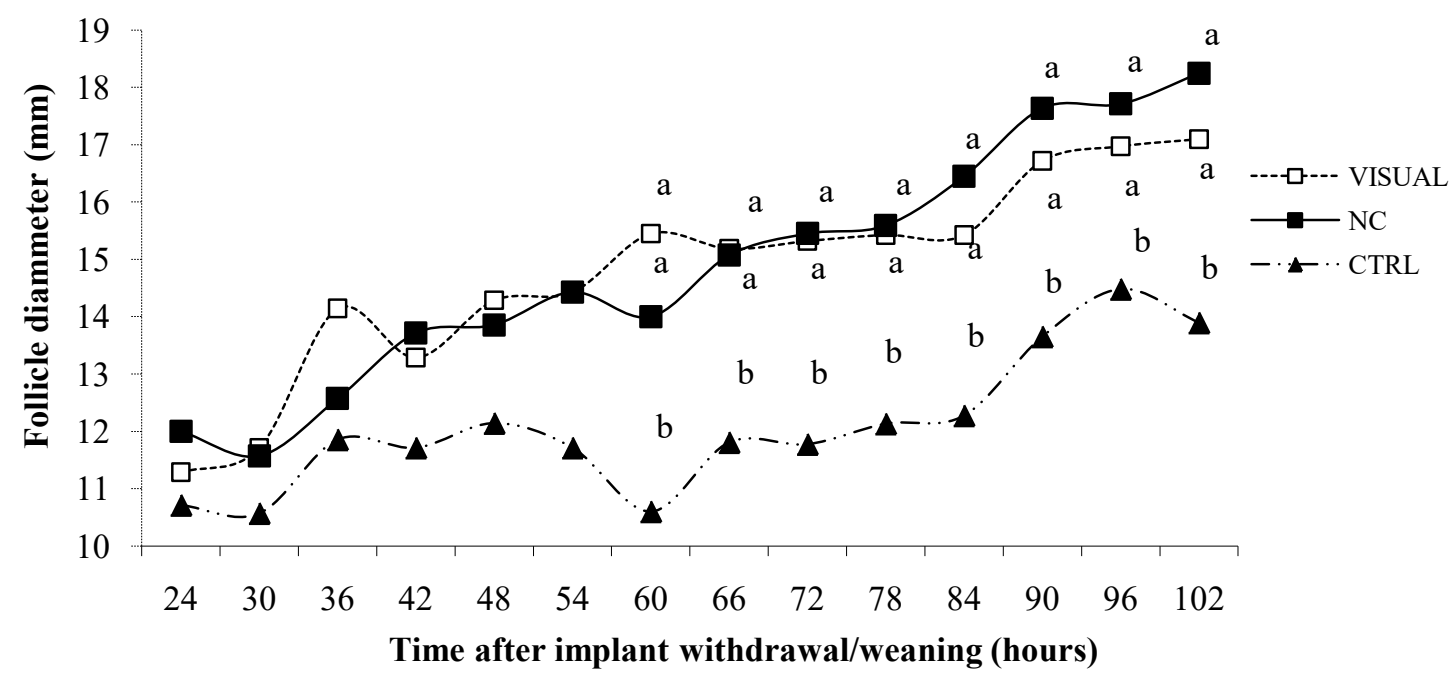

Figure 3. Effect of the presence or absence of the calf after an estrous synchronization program on dominant follicle diameter in postpartum Bos indicus cows; VISUAL = calves partially removed; NC = calves completely removed; $\mathrm{CTRL}=$ calves were not removed; Different superscripts among time points denotes a difference $(\mathrm{P}<0.05)$.

\section{Discussion}

Many factors influence the resumption of ovarian activity postpartum such as nutrition, environmental age and genetics (Jolly et al., 1995). One of the most important factors is the effect of suckling. Cows that were nursing calves delayed the resumption of ovarian follicular growth, ovulation and establishment of a normal lifespan CL (Abeygunawardena and Dematawewa, 2004). Reducing the time that the cow nurses a calf by partial or total weaning procedures increases the number of animals that resume ovarian activity and ovulate (Perea et al., 2008; Pinheiro et al., 2009; Perez-Torres et al., 2015).

Rhodes et al. (2003) reported that treating anestrous cows with progestagen plus estradiol induces estrus response and ovulation in almost $90 \%$ of the cows. In contrast, only $54 \%$ of the cows exhibited estrus and $60 \%$ had ovulations in the present study. Findings more consistent with a previously reported $50 \%$ response rate in Zebu-type cattle (Vasconcelos et al., 2009; Sá Filho et al., 2009; Hernandez et al., 2015). Incidence of estrus was enhanced by weaning. The percentage of cows in estrus in the present study was twice that of cows in the control treatment (cows that had a synchronized time of estrus and their offspring not removed). This result is consistent with previous evidence that calf separation has a dramatic effect on estrous expression regardless of the method used to separate the calves (Williams et al., 1996; Quintans et al., 2009, Quintans et al., 2010).

Cows with calf contact had a greater tendency 
to display overt signs of estrus $(76.5 \%)$ than those with no calf contact $(58.8 \%)$. A similar tendency was observed in the proportion of ovulating cows $(76.0 \%$ compared with $64.0 \%$, respectively). Comparable results were previously observed (Webb et al., 2004) where $65 \%$ of animals subjected to partial weaning of their calves ovulated after the estrous synchronization program was imposed. Progestagen is another factor that could improve ovulation rates; however, its effectiveness is reported to be variable, ranging between a success rate of between 5 and $70 \%$ to induce estrus and ovulation (Day, 2004; Perez-Torres et al., 2015). In the present study, regardless of the separation method used, an average of $60 \%$ of dams ovulated.

Earlier studies demonstrated that GnRH release is suppressed in suckling beef cows; consequently the episodic release of $\mathrm{LH}$ is inhibited affecting ovarian follicular growth (Yavas and Walton, 2000). The recovery of the episodic secretion pattern has been reported to occur between 15 and 30 days postpartum. LH concentration increased around $36 \mathrm{~h}$ after implant withdrawal/weaning in all groups. However, in the CTRL group there was a statistically different LH concentration at $54 \mathrm{~h}$ probably due to the effect of calf separation together with the hormonal treatment, favoring GnRH release followed by LH secretion. In the case of the CTRL animals, increase in LH was probably induced by the hormonal treatment alone.

Results of the present study are consistent with those of Maquivar et al. (2007) who found an increase in LH occurring in the lead-up to ovulation. This increase occurred around $24 \mathrm{~h}$ in estrous cycling Bos indicus cows synchronized with use of a progestagen. Regardless of the weaning treatment, cows ovulated 25 $h$ after the pre-ovulatory surge of LH release. Interestingly, dominant follicular diameter was greater in the weaning treatments than in the CTRL group starting at $60 \mathrm{~h}$ post implant withdrawal/weaning. Similar reports have been published recently (Mondragon et al., 2016). This trend continued until the end of the ultrasonic assessments in the present study. Our results suggest agreement with previous observations that cows with smaller follicles have less opportunity to become pregnant (Sá Filho et al., 2009).

Weaning combined with the use of hormonal treatment was shown in the present study to be effective for inducing estrus and establishing estrous cycles, confirming earlier studies that weaned cows have a tendency to an earlier onset of estrous cycles, thus increasing the probability of becoming pregnant at the onset of the breeding season. Further research is necessary on the impact of the weaning procedure on cortisol levels and/or stress that may impede the onset of estrus and/or ovulation. Pérez et al. (2017) reported minor differences in cortisol levels between treatments and control. However, in-depth study on the effect of weaning on specific metabolic parameters such as adipose tissue mobilization and estradiol concentration is needed.

Results from the present experiment indicate that calf removal but allowing contact with dams increased the number of ovulating cows and shortened the time to the initiation of estrous cycles following calving. Both treatments (VISUAL and NC) induced a more homogeneous response in ovarian follicular growth and LH pattern compared with cows from the CTRL group.

\section{Conflict of interest}

The authors declare that they have no conflict of interest.

\section{References}

Abeygunawardena H, Dematawewa C. 2004. Prepuberal and postpartum anestrus in tropical Zebu cattle. Anim Reprod Sci, 82:83, 373-387.

Baruselli PS, Reis EL, Marques MO, Nasser LF, Bó GA. 2004. The use of hormonal treatments to improve reproductive performance of anestrous beef cattle in tropical climates. Anim Reprod Sci, 82:83, 479-86.

Chenoweth PJ. 1994. Aspects of reproduction in female Bos indicus cattle: a review. Aust Vet J, 71:422426.

Day ML. 2004. Hormonal induction of estrous cycles in anestrous Bos taurus beef cows. Anim Reprod Sci, 82:83, 487-494.

Díaz R, Galina CS, Rubio I, Corro M, Pablos JL, Rodríguez A, Orihuela A. 2017. Resumption of ovarian function, the metabolic profile and body condition in Brahman cows (Bos indicus) is not affected by the combination of calf separation and progestogen treatment. Anim Reprod Sci, 185:181-187

Edmonson AJ, Lean IJ, Weaver LD, Farver T, Webster G. 1989. A body condition score chart for Holstein cows. J Anim Sci, 72:68-78.

Galina CS, Arthur GH. 1989. Review of cattle reproduction in the tropics. Part 3. Puerperium. Breed Abstr, 57:899-910.

Hernández A, Galina CS, Diaz R, Rubio I, Corro M, Romero JJ. 2015. Comparison of two insemination programs in synchronized early postpartum zebu cows under tropical conditions. An economic appraisal. Open Vet $J, 234-242$

Hoffman DP, Stevenson JS, Minton JE. 1996 Restricting calf presence without suckling compared with weaning prolongs postpartum anovulation in beef cattle. J Anim Sci, 74:190-198.

Jolly PD, McDougall S, Fitzpatrick LA, Macmillan KL, Entwistle, KW. 1995. Physiological effects of undernutrition on postpartum anoestrus in cows. $J$ Reprod Fertil Suppl, 49:477-492.

Lamb GC, Miller BL, Lynch JM, Thompson KE, Heldt JS, Löest CA, Grieger DM, Stevenson J. 1999. Twice daily suckling but not milking with calf presence prolongs postpartum anovulation. J Anim Sci, 77:22072218.

Maquivar M, Veduzco A, Galina CS, Pulido A, Rojas S, Forster K, Van der Laan G, Arnoni R. 2007. Relationship among follicular growth, oestrus, time of ovulation, endogenous estradiol $17 \beta$ and luteinizing hormone in Bos indicus cows after a synchronization program. Reprod Domest Anim, 


\section{2:571-576}

Mikeska JC, Williams GL. 1988. Timing of preovulatory endocrine events, estrus and ovulation in Brahman $\mathrm{x}$ Hereford females synchronized with Norgestomet and Estradiol Valerate. J Anim Sci, 66: 939-946.

Mondragón V, Galina CS, Rubio I, Corro M, Salmerón F. 2016. Effect of restricted suckling on the onset of follicular dynamics and body condition score in Brahman cattle raised under tropical conditions Anim Reprod Sci, 161:89-95.

Orihuela A, Galina CS, Escobar J, Riquelme E. 1983. Oestrous behaviour following prostaglandin F2a injection in Zebu cattle under continuous observation. Theriogenology, 19:795-809.

Perea FP, De Ondiz AD, Palomares RA, Hernández HJ, González R, Soto ER. 2008. Control of postpartum anestrous with an intra-vaginal progesterone device plus eCG or calf removal for $120 \mathrm{~h}$ in suckled crossbred cows managed in a pasture-based system. Anim Reprod Sci, 106:298-310.

Perera-Marin G, Murcia C, Rojas S, HernandezCeron J, Gonzalez-Padilla E 2005. Pattern of circulating luteinizing hormone isoforms during the estrous and luteal phases in Holstein heifers. Anim Reprod Sci, 86:53-69.

Pérez LI, Orihuela A, Galina CS, Rubio I, Corro M, Cohen A, Hernandez A. 2017. Effect of different periods of maternal deprivation on behavioral and cortisol responses at weaning and subsequent growth rate in Zebu (Bos indicus) type cattle". Livest Sci, 197:17-21.

Pérez-Torres L, Rubio I, Corro M, Cohen A, Orihuela A, Galina CS Pablos JL. 2015. A pre synchronization program at early postpartum might increase the chances of Bos indicus cows cycling prior to 50 days regardless of the length of calf separation. $J$ Reprod Dev, 61:199-2003.

Pinheiro VG, Souza AF, Pegorer MF, Satrapa RA, Ereno RL, Trinca LA, Barros CM. 2009. Effects of temporary calf removal and eCG on pregnancy rates to timed-insemination in progesterone-treated postpartum Nellore cows. Theriogenology, 71:519-524.

Quintans G, Vázquez AI, Weigel KA. 2009. Effect of suckling restriction with nose plates and premature weaning on postpartum anestrous interval in primiparous cows under range conditions. Anim Reprod
Sci, 116:10-18.

Quintans G, Banchero G, Carriquiry M, LópezMazz C, Baldi F. 2010. Effect of body condition and suckling restriction with and without presence of the calf on cow and calf performance. Anim Prod Sci, 50:931-938.

Rhodes FM, McDougall S, Burke CR, Verkek GA, Macmillan KL 2003. Treatment of cows with an extended postpartum anestrous interval. Review. $J$ Dairy Sci, 86:1876-1894.

Sá Filho OG, Meneghetti M, Peres RFG, Lamb GC, Vasconcelos JLM. 2009 Fixed-time artificial insemination with estradiol and progesterone for Bos indicus cows II: Strategies and factors affecting fertility. Theriogenology, 72:210-218.

Sartori R, Bastos MR, Baruselli PS, Gimenes LU, Ereno RL, Barros CM. 2010. Physiological differences and implications to reproductive management of Bos taurus and Bos indicus cattle in a tropical environment. Soc Reprod Fertil Suppl, 67:357375.

SAS Institute Inc. 2004. SAS OnlineDoc ${ }^{\circledR}$ 9.1.2. Cary, $\mathrm{NC}, \mathrm{USA}$ : SAS Institute Inc.

Ungerfeld R, Hötzel MJ, Scarsi A, Quintans G. 2011. Behavioral and physiological changes in early-weaned multiparous and primiparous beef cows. Animal, 5:1270-1275.

Vasconcelos JLM, Sá Filho OG, Campos PG, Nogueira SAT. 2009. Intravaginal progesterone and/or temporary weaning on reproductive performance of anestrous crossbred Angus x Nelore cows. Anim Reprod Sci, 111:302-311.

Viker SD, Larson RL, Kiracofe GH, Stewart RE, Stevenson JS. 1993. Prolonged postpartum anovulation in mastectomized cows requires tactile stimulation by the calf. J Anim Sci, 71:999-1003.

Webb C, Galina CS, Molina R, Maquivar M, Estrada S. 2004. Effect of two types of weaning and the application of a progestagen on the fertility in Bos indicus cattle. Arch Med Vet, 36:147-154.

Williams GL. 1990. Suckling as a regulator of postpartum rebreeding in cattle. J Anim Sci, 68: 831-852.

Williams GL, Gazal OS, Guzman GA, Stanko RL. 1996. Mechanisms regulating suckling mediated anovulation in the cow. Anim Reprod Sci, 42:289-297.

Yavas Y, Walton JS. 2000. Postpartum acyclicity in suckled beef cows: a review. Theriogenology, 54:25-55. 